\title{
Improving doctor-patient communication: content validity examination of a novel urinary system- simulating physical model
}

This article was published in the following Dove Press journal:

Patient Preference and Adherence

13 December 2016

Number of times this article has been viewed

\section{WenGang Hu \\ YaJun Song \\ Xiao Zhong \\ JiaYu Feng \\ PingXian Wang \\ ChiBing Huang}

Department of Urology, Second Affiliated Hospital, Third Military Medical University, Chongqing,

People's Republic of China
Correspondence: ChiBing Huang Department of Urology, Second Affiliated Hospital, Third Military Medical University, No 183, XinQiao Street, ShaPingBa District, Chongqing, 400037, People's Republic of China

Tel +8602368755 I 4 I

Fax +8602368755306

Email huangchibing@medmail.com.cn

\begin{abstract}
Effective doctor-patient communication is essential for establishing a successful doctor-patient relationship and implementing high-quality health care. In this study, a novel urinary system-simulating physical model was designed and fabricated, and its content validity for improving doctor-patient communication was examined by conducting a randomized controlled trial in which this system was compared with photographs. A total of 240 inpatients were randomly selected and assigned to six doctors for treatment. After primary diagnosis and treatment had been determined, these patients were randomly divided into the experimental group and the control group. Patients in the experimental group participated in model-based doctor-patient communication, whereas control group patients received picture-based communication. Within 30 min after this communication, a Demographic Information Survey Scale and a Medical Interview Satisfaction Scale (MISS) were distributed to investigate patients' demographic characteristics and their assessments of total satisfaction, distress relief, communication comfort, rapport, and compliance intent. The study results demonstrated that the individual groups were comparable with respect to demographic variables but that relative to patients in the picture-based communication group, patients in the model-based communication group had significantly higher total satisfaction scores and higher ratings for distress relief, communication comfort, rapport, and compliance intent. These results indicate that the physical model is more effective than the pictures at improving doctor-patient communication and patient outcomes. The application of the physical model in doctor-patient communication is helpful and valuable and therefore merits widespread clinical popularization.
\end{abstract}

Keywords: doctor-patient communication, doctor-patient relationship, model, urology

\section{Introduction}

Doctor-patient communication has been shown to be fundamental in clinical practice, and the main goals of communication have been to create good interpersonal relationships, to facilitate the exchange of information, and to include patients in decisionmaking. ${ }^{1-4}$ In contemporary medicine, communication has been gaining increasing attention as more health care providers have recognized that it is essential to health. Studies have shown that good doctor-patient communication can enhance the doctorpatient relationship, improve patient satisfaction with medical encounters, and decrease patients' psychological stress and symptoms and was associated with improved trust in health care providers, increased satisfaction with care, greater patient confidence in and adherence to treatment plans, and improved medical outcomes. ${ }^{6-10}$ Inversely, poor communication and attitudes between the doctor and patient constitute the most frequent underlying cause of malpractice litigation, complaints against doctors, and 
nonadherence to medication regimens. ${ }^{11-14}$ Thus, developing strategies to strengthen communication has become a central topic in clinical and social research. Given this phenomenon, in this study, a novel urinary system-simulating physical model was designed and fabricated, and a randomized controlled trial was performed to test this model's content validity for improving doctor-patient communication by comparing the model with pictures.

\section{Materials and methods \\ Model fabrication and pictures preparation}

The model, which was based on human anatomical structure, was designed using UG NX software. Figure 1 presents one of the images of the male urinary system created during the design process. All images were retained and printed for use as pictures assessed in the content validity trial. The physical model designed based on these images was then fabricated using MasterCAM software and a CNC machine. The main components included in the model were the kidneys, ureters, bladder, prostate, and urethra: the model was created using transparent acrylic and silicone rubber. Figure 2 shows the male urinary system-simulating physical model. It is transparent and anatomically accurate, and could be used to demonstrate multiple clinical abnormalities and operations, including lithiasis in the urinary system, obstructions, tumors,

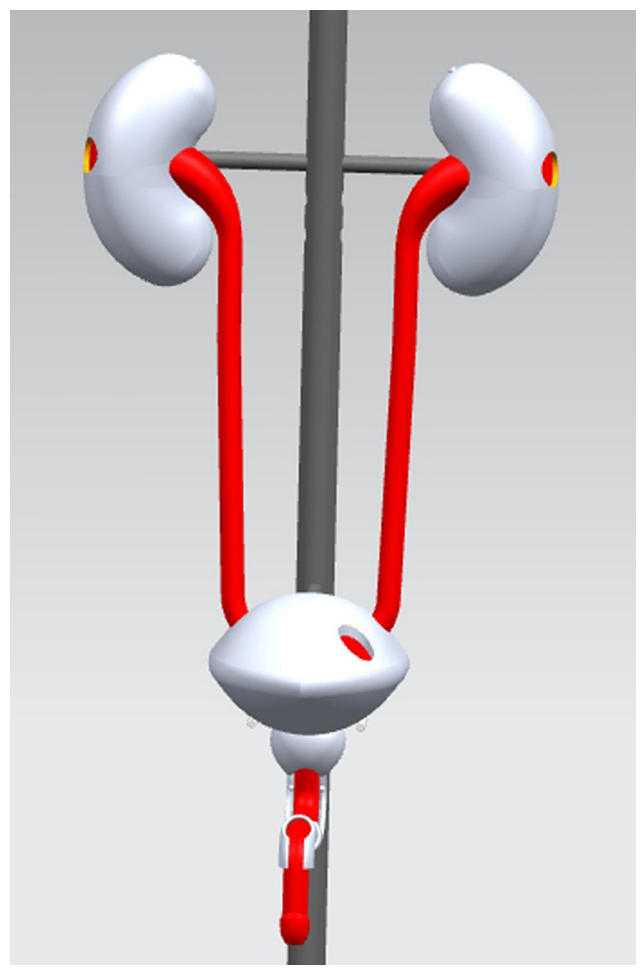

Figure I One design image of the male urinary system.

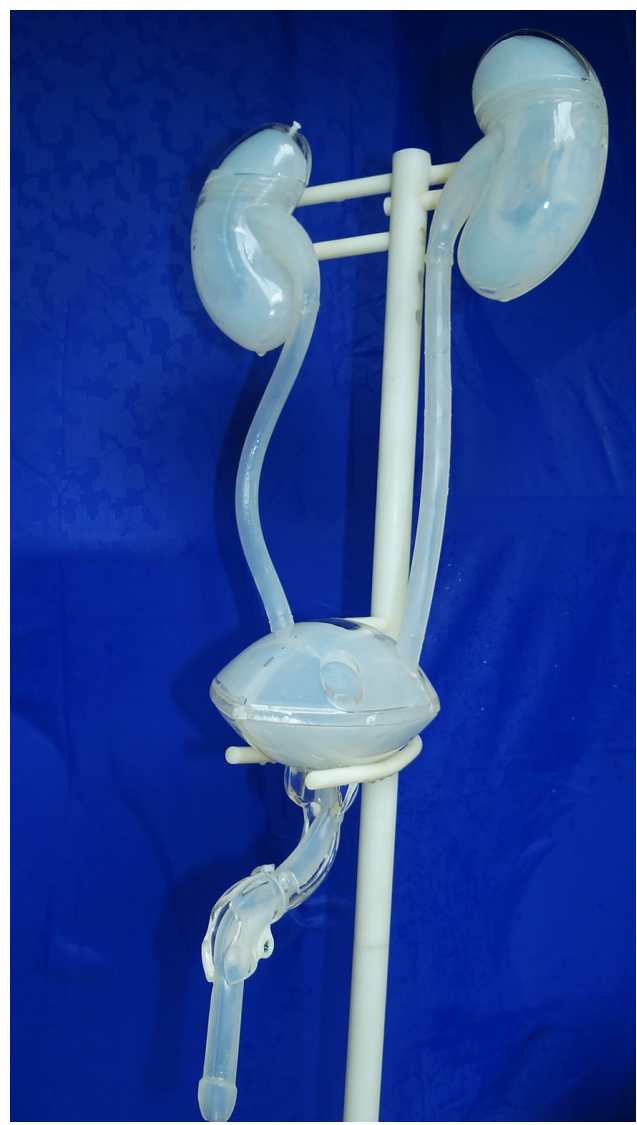

Figure $\mathbf{2}$ The male urinary-system-simulating physical model.

catheterization, cystoscopy, ureteroscopy, and ureteral stent insertion and removal. ${ }^{15}$

\section{Content validity examination}

\section{Participants and grouping}

The study protocol was approved by the ethics committee of the XinQiao Hospital (Second Affiliated Hospital of Third Military Medical University) in China and was conducted in the Urology Department from 2012 to 2013. The design involved a randomized trial with two arms (model-based communication and pictures-based communication). Six urologists, who were selected through stratified sampling by professional qualification (chief physician, associate chief physician, attending physician, resident [1:1:1:3]) from the 12 urologists in the Urology Department of the XinQiao Hospital, participated in the research. Two specific researchers were assigned to take charge of random allocation, conduct the questionnaire investigation, and collect the data. A total of 240 inpatients aged $\geq 18$ years were invited to attend the study and given an informed consent form. Patients who were blind, in a coma, unable to speak Chinese, or suffering from a major mental illness were excluded from the study. 


\section{Research procedure}

Considering seasonal prevalence differences, the study was conducted over four seasons: that is, 60 inpatients were randomly selected to join the research every 3 months. Starting on the first workday of each season, two specific researchers observed newly admitted patients and identified eligible patients. Before determining the physician in charge, eligible patients were contacted by the two specific researchers. Upon contact, the researchers informed the patients about this study opportunity and invited them to participate. Patients who consented verbally and completed the consent form were included in the study and then randomly assigned to one of the six doctors for treatment. After the primary diagnosis and treatment were determined, within $48 \mathrm{~h}$ after admission, the patients were randomized to the experimental group (model-based communication group) or control group (pictures-based communication group) by the two researchers, using a random number table. The doctor in charge then conducted communication according to the protocol of each group. In the model-based communication group, the surgeons were required to take advantage of the model's anatomy or demonstrating function while explaining the region and cause of a lesion, the possible progress of the disease, and the therapies and surgical procedures that were planned or being conducted. Because the model is transparent, the patients can observe the internal anatomical structure and various operating states inside. Figure 3 shows one doctor explaining the purpose and method of ureteral stent insertion to a patient. Figure 4 shows the stent in the model. In the picture-based group, the surgeons were asked to use the model-design pictures to conduct communication without the model. The communication content of the groups referenced the research of Hagihara and Tarumi ${ }^{16}$ and primarily included, 1) the medical testing and examination; 2) the cause and diagnosis; 3 ) the treatment and its effects; 4) the side effect and treatment risks; and

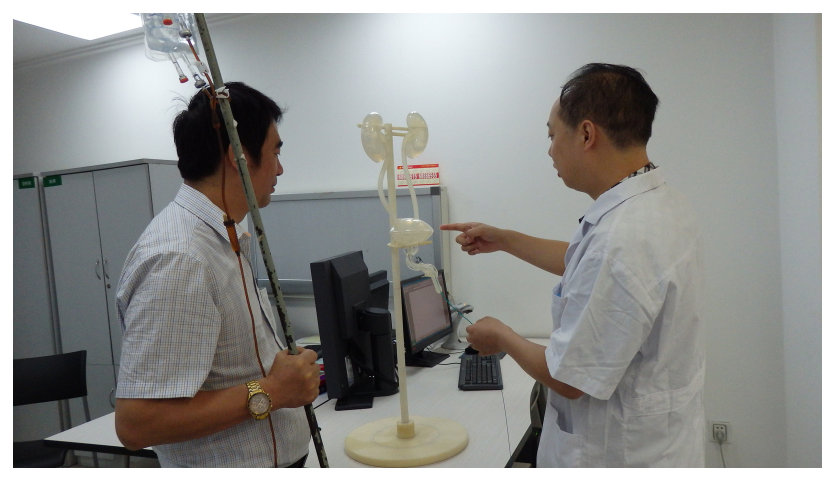

Figure 3 One doctor was explaining the ureteral stent insertion.

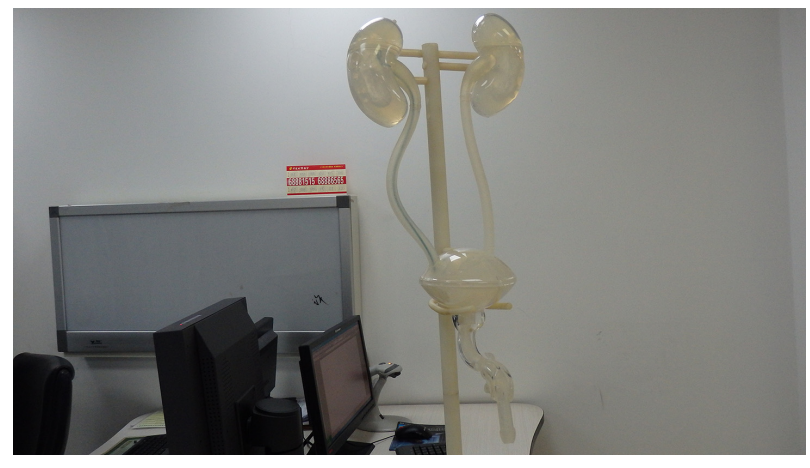

Figure 4 The stent in the model.

5) the prognosis of the disease and patient precautions: the time for communicating was $20 \mathrm{~min}$. Each season's study continued until the research task was accomplished with 60 patients.

\section{Measures and statistical analyses}

Within 30 min after the communication and in the absence of the physician, the two specific researchers conducted a questionnaire investigation. The patients were asked to complete a Demographic Information Survey Scale to elicit demographic information, including sex, age, level of education, first diagnosis, and whether the occurrence was the first hospitalization, and they were required to complete the Medical Interview Satisfaction Scale (MISS) (Supplementary materials). ${ }^{17,18}$ The MISS consisted of 29 questions that provided a measure of overall patient satisfaction, and its four subscales can be used to assess, 1) distress relief, 2) communication comfort, 3) rapport, and 4) compliance intent. All subjects were asked to provide an opinion on a 7-point Likert scale for each question, with the answer "very strongly disagree" at 1 and the answer "very strongly agree" at 7. The subscale and total scores were calculated by simply adding all item scores without weighting; thus, the qualitative assessment had a potential minimal score of 29 and a maximum of 203 points. The results were sent to the research group: another two researchers independently conducted the data analysis and statistics with SPSS software, version 10.0. The differences in the demographic information and the evaluation were compared using the chi-square test or the independent-samples $t$-test. Statistical significance was accepted at $P<0.05$.

\section{Results}

\section{Participants}

Of the six surgeons, one (male) was a chief physician, and two (males) were associate chief physician and attending physician, and three were residents (two males and one female). 
The average age of the surgeons was 36 years (SD 9.84; range 27-49), and the average career length was 11.17 years (SD 9.79; range 3-24). The six doctors were eligible to participate in the study. All of these individuals completed every procedure in strict accordance with the study program and consented to allowing images obtained during this study to be used in this article, and none of the doctors dropped out at the halfway point of the trial. A total of 257 inpatients were identified, of whom 246 were eligible. A total of 240 inpatients voluntarily participated in the research: 120 in the experimental group and 120 in the control group, and all of the patients consented to the inclusion of their data in the analysis. Figure 5 shows the participant flow of the randomized controlled trial.

\section{Demographic characteristics}

Of the patients in the experimental group, 80 were males (Table 1) and 40 were females: 20 were aged 18-32 years, 35 were aged 33-47 years, 39 were aged 48-62 years, and 26 were aged $\geq 63$ years; 49 had less than a middle school education, 37 had a middle school or a high school education, and 34 had more than a high school education; 19 patients had renal failure, 49 had urolithiasis, 23 had obstruction of the urinary tract, 18 had tumors, and 11 had other medical conditions; 76 stated it was their first hospitalization, and 44 had been hospitalized more than once. In the control group, 85 were males and 35 were females: 14 were aged 18-32 years, 33 were aged 33-47 years, 36 were aged 48-62 years, and 37 were aged $\geq 63$ years; 57 had less than a middle school education, 22 had a middle school or a high school education, and 41 had more than a high school education; 26 patients had renal failure, 38 had urolithiasis, 29 had obstruction of the urinary tract, 21 had tumors, and 6 had other medical conditions; 74 stated it was their first hospitalization, and 36 had been hospitalized more than once. According to the Chi-square test, no differences were determined between the groups with regard to sex $\left(\chi^{2}=0.485, P=0.486\right)$, age divisions $\left(\chi^{2}=3.158, P=0.368\right)$, levels of education $\left(\chi^{2}=2.223, P=0.329\right)$, illness categories $\left(\chi^{2}=4.873, P=0.301\right)$, or whether it was a first or subsequent hospitalization $\left(\chi^{2}=0.071, P=0.790\right)$.

\section{Patient assessment}

In the evaluation survey, the model-based communication group and pictures-based communication group received means of $148.44 \pm 18.97$ and $141.66 \pm 20.92$ ( $P=0.009)$, respectively, in terms of total satisfaction (Table 2). Additionally, on the MISS subscales, the experimental group and the

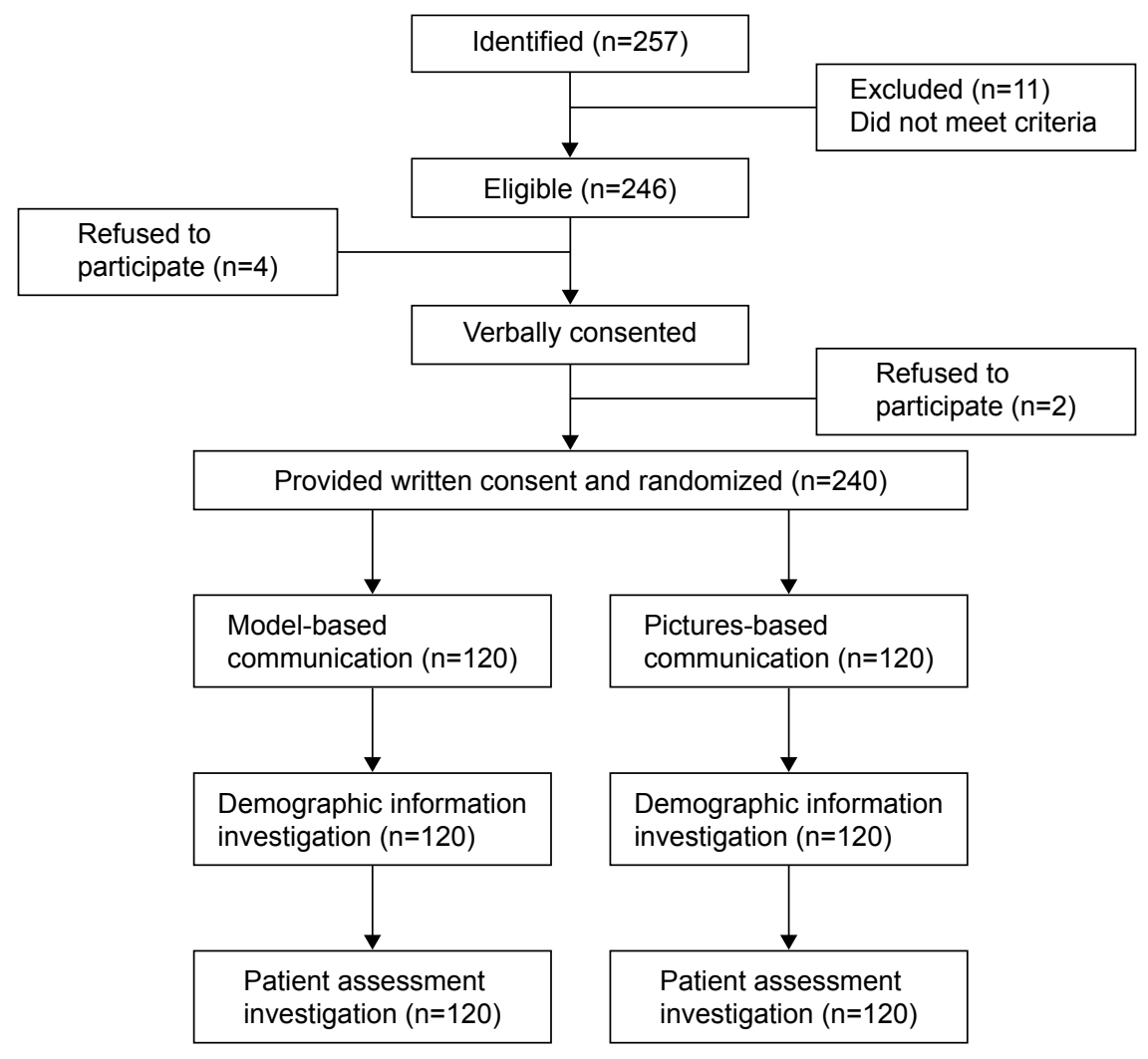

Figure $\mathbf{5}$ The participant flow of the randomized controlled trial. 
Table I Demographic characteristics

\begin{tabular}{|c|c|c|c|c|}
\hline Characteristics & No in experimental group & No in control group & $x^{2}$ & $P$-value \\
\hline Sex & & & 0.485 & 0.486 \\
\hline Male & 80 & 85 & & \\
\hline Female & 40 & 35 & & \\
\hline Age division (years) & & & 3.158 & 0.368 \\
\hline $18-32$ & 20 & 14 & & \\
\hline $33-47$ & 35 & 33 & & \\
\hline $48-62$ & 39 & 36 & & \\
\hline$\geq 63$ & 26 & 37 & & \\
\hline Level of education & & & 2.223 & 0.329 \\
\hline Less than middle school & 49 & 57 & & \\
\hline Middle school to high school & 37 & 22 & & \\
\hline More than high school & 34 & 41 & & \\
\hline Illness category & & & 4.873 & 0.301 \\
\hline Renal failure & 19 & 26 & & \\
\hline Urolithiasis & 49 & 38 & & \\
\hline Obstruction & 23 & 29 & & \\
\hline Tumor & 18 & 21 & & \\
\hline Other & 11 & 6 & & \\
\hline First hospitalization or not & & & 0.071 & 0.790 \\
\hline First & 76 & 74 & & \\
\hline Not the first & 44 & 46 & & \\
\hline Total & 120 & 120 & & \\
\hline
\end{tabular}

control group scored 56.04 \pm 6.46 and 53.88 $\pm 7.43(P=0.017)$ for distress relief, $19.92 \pm 2.96$ and $18.55 \pm 3.51 \quad(P=0.001)$ for communication comfort, 52.25 \pm 7.75 and $49.96 \pm 8.94$ $(P=0.035)$ for rapport, and $20.23 \pm 2.93$ and $19.27 \pm 3.42$ $(P=0.019)$ for compliance intent. All of the rating scores from the experimental group were higher than those from the control group (Table 2).

\section{Discussion}

Medicine involves the integration of not only art and science but also magic and creative ability, and the building of a harmonious patient-physician relationship reflects this artistic quality. ${ }^{19,20}$ Research focusing on the concerns of clinical physicians has been extensive. Studies have found that attentive and respectful listening in communication reinforced the healing process and positively affected patient satisfaction; ${ }^{21-23}$ theater training was effective at teaching clinical empathy; ${ }^{24}$ empathic responses during doctorpatient information exchanges were consistently associated with positive patient outcome, stable patient adherence, and symptom resolution; ${ }^{25-30}$ a physician's attention to a computer monitor diminished dialogue between the physician and the patient and was inversely correlated with the effect of communication; ${ }^{31}$ and audiovisual aids, such as figures, pictures, DVDs, and MP3 files, were helpful for transferring medical information, promoting doctor-patient communication, and improving patient comprehension, recall, and adherence. ${ }^{32-35}$ To our knowledge, there have been few or no studies with regard to the effectiveness of a simulator or anatomic model in promoting doctor-patient communication and improving patient outcomes.

This article, along with randomized, controlled trials, compared the content validity of a novel urinary systemsimulating physical model with that of pictures in improving

Table 2 Impact of intervention on patient and doctor satisfaction

\begin{tabular}{llll}
\hline Investigation issue & Mean \pm SD & & \\
\cline { 2 - 3 } & Experimental group & Control group & \\
\cline { 2 - 4 } & $148.44 \pm 18.97$ & $141.66 \pm 20.92$ & \\
Patient satisfaction (Total MISS) & & & 0.009 \\
MISS subscales & $56.04 \pm 6.46$ & $53.88 \pm 7.43$ & 0.017 \\
$\quad$ Distress relief & $19.92 \pm 2.96$ & $18.55 \pm 3.51$ & 0.001 \\
Communication comfort & $52.25 \pm 7.75$ & $49.96 \pm 8.94$ & 0.035 \\
Rapport & $20.23 \pm 2.93$ & $19.27 \pm 3.42$ & 0.019 \\
Compliance intent & & & \\
\hline
\end{tabular}

Abbreviations: MISS, Medical Interview Satisfaction Scale; SD, standard deviation. 
doctor-patient communication and patient satisfaction. In our experimental design, we found that patients of different sexes $^{36-40}$ and with different hospitalization frequencies, ${ }^{36}$ ages, ${ }^{41-43}$ education levels, ${ }^{44}$ and health conditions ${ }^{45}$ had diverse needs in communication and different opinions when evaluating doctors and their own patient satisfaction; thus, these patient characteristics influenced clinical communication. In this research, it was demonstrated that there was no significant difference in the aspects cited above when comparing the experimental group to the control group according to the statistical data, and almost all of the interventions that might have affected the research results were excluded, ensuring that our results and conclusions were objective and reliable.

Consequently, the significant differences in the evaluations between the experimental and control groups indicated that the following conclusions can be drawn: model-based communication seems to be more effective in affecting patient satisfaction, promoting patient distress relief, increasing communication comfort, enhancing patient compliance, strengthening doctor-patient relationship, and improving patient outcomes compared to picture-based communication. These results were consistent with our expectations. It is well known that relative to dissatisfied patients, satisfied patients are less likely to lodge formal complaints or initiate malpractice proceedings; ${ }^{19,46-48}$ moreover, patient satisfaction is advantageous for doctors with respect to increased job satisfaction, reduced fatigue, and relief from work-related stress. ${ }^{1,49}$ As a result, it can reduce the litigation costs of hospitals and promote the development of a harmonious and stable medical environment, and it is beneficial to hospitals, clinical medicine, and medical research. Along with its effectiveness in improving patient outcomes, which reduces expenses for patients, model-based communication can benefit both the medical practice and the patients.

When considering the factors that led to the significant difference observed between the two groups, we speculated that the authenticity of the model played an important role. During a patient consultation, the use of the physical model to explain and analyze diseases and treatments is more intuitive and vivid than the use of pictures, which provide less direct representations. As a result, model use enhanced patients' understanding of medical information and relieved patient distress.

Actually, it was appropriate to expand the study values in light of the entire article, and the important attributes of the model used were anatomically accurate, with a functional presentation. This study hypothesizes that other simulation models of the urinary system or simulators of other systems will also be useful in related clinical departments to increase patient satisfaction and improve patient compliance and outcomes.

Another advantage of model-based communication was its convenience in generalization and application. First, this physical model was economical and easy to fabricate. Moreover, other physical simulation models are convenient to purchase because many economical simulators and anatomical models exist on the market. Furthermore, model-based communication was easy to implement in the clinic, with no particular training required. If the doctor was familiar with the structure and function of a simulator, he or she could undertake interactive and vivid communication with patients soon. This was extremely meaningful, particularly in geographic areas with poor education and training in communication skills, and model-based communication could be used to alleviate doctor-patient conflicts and to ameliorate effectively and promptly the tensions of the doctor-patient relationship. Admittedly, useful communication skills are essential in clinical communication, but we firmly believe that modelbased communication can serve as a supplementary approach to improve the quality of communication and health care.

One limitation of this study was that the number of doctors included in the trials was insufficient, and although it included chief physicians, associate chief physicians, attending physicians and residents, the number of physicians at each level was limited. Another limitation was that it was not clear whether the application of the model enhanced the patients' recall of the necessary information. In addition, it cannot be determined which type of doctor this communication mode was more beneficial for, nor the type of patients for whom this communication mode was more applicable. We will conduct further research on these issues.

\section{Conclusion}

Our study designed and fabricated a novel urinary systemsimulating physical model. The model's content validity in improving doctor-patient communication was confirmed by comparing its use with the use of pictures. This comparison demonstrated that the application of the physical model was more effective in promoting doctor-patient communication, relieving patient distress, enhancing patient compliance, strengthening the doctor-patient relationship, and improving patient outcomes, compared to the pictures. With demonstrated effectiveness in improving patient satisfaction and convenience of application, model-based communication merits widespread popularization. It could be used to alleviate 
doctor-patient conflicts and to effectively ameliorate the tensions of the doctor-patient relationship.

\section{Acknowledgments}

The authors wish to thank MingQi Fan for assistance with statistical analysis and RongHua $\mathrm{Wu}$ and YiRong Chen for participating in the study. The authors also gratefully acknowledge financial support from the Scientific and Technological Achievements Fund (2011XZH05, 2012XZH04) and the Clinical Research Fund of the Third Military Medical University of China (2008XLC15).

\section{Disclosure}

The authors report no conflicts of interest in this work.

\section{References}

1. Brédart A, Bouleuc C, Dolbeault S. Doctor-patient communication and satisfaction with care in oncology. Curr Opin Oncol. 2005;17(4): 351-354.

2. Arora NK. Interacting with cancer patients: the significance of physicians' communication behavior. Soc Sci Med. 2003;57(5):791-806.

3. Lee SJ, Back AL, Block SD, Stewart SK. Enhancing physician-patient communication. Hematology Am Soc Hematol Educ Program. 2002; 464-483.

4. Platt FW, Keating KN. Differences in physician and patient perceptions of uncomplicated UTI symptom severity: understanding the communication gap. Int J Clin Pract. 2007;61(2):303-308.

5. Frist WH. Shattuck lecture: health care in the 21 st century. NEngl J Med. 2005;352(3):267-272.

6. Brown JB, Boles M, Mullooly JP, Levinson W. Effect of clinician communication skills training on patient satisfaction. A randomized, controlled trial. Ann Intern Med. 1999;131(11):822-829.

7. Pendleton L, House WC, Parker LE. Physicians' and patients' views of problems of compliance with diabetes regimens. Public Health Rep. 1987;102(1):21-26.

8. Richards T. Chasms in communication. BMJ. 1990;301(6766): 1407-1408.

9. Stewart MA. Effective physician-patient communication and health outcomes: a review. CMAJ. 1995;152(9):1423-1433.

10. Williams S, Weinman J, Dale J. Doctor-patient communication and patient satisfaction: a review. Fam Pract. 1998;15(5):480-492.

11. Jenkins L, Britten N, Stevenson F, Barber N, Bradley C. Developing and using quantitative instruments for measuring doctor-patient communication about drugs. Patient Educ Couns. 2003;50(3):273-278.

12. Lefevre FV, Waters TM, Budetti PP. A survey of physician training programs in risk management and communication skills for malpractice prevention. J Law Med Ethics. 2000;28(3):258-266.

13. Levinson W. Physician-patient communication. A key to malpractice prevention. JAMA. 1994;272(20):1619-1620.

14. Shapiro RS, Simpson DE, Lawrence SL, Talsky AM, Sobocinski KA, Schiedermayer DL. A survey of sued and nonsued physicians and suing patients. Arch Intern Med. 1989;149(10):2190-2196.

15. Hu WG, Feng JY, Wang J, et al. Ureteroscopy and cystoscopy training: comparison between transparent and non-transparent simulators. $B M C$ Med Educ. 2015;15:93.

16. Hagihara A, Tarumi K. Doctor and patient perceptions of the level of doctor explanation and quality of patient-doctor communication. Scand J Caring Sci. 2006;20(2):143-150.

17. Kinnersley P, Stott N, Peters T, Harvey I, Hackett P. A comparison of methods for measuring patient satisfaction with consultations in primary care. Fam Pract. 1996;13(1):41-51.
18. Wolf MH, Putnam SM, James SA, Stiles WB. The Medical Interview Satisfaction Scale: development of a scale to measure patient perceptions of physician behavior. J Behav Med. 1978;1(4):391-401.

19. Ha JF, Longnecker N. Doctor-patient communication: a review. Ochsner J. 2010;10(1):38-43.

20. Hall JA, Roter DL, Rand CS. Communication of affect between patient and physician. J Health Soc Behav. 1981;22(1):18-30.

21. Clark NM, Cabana MD, Nan B, et al. The clinician-patient partnership paradigm: outcomes associated with physician communication behavior. Clin Pediatr (Phila). 2008;47(1):49-57.

22. Jagosh J, Donald Boudreau J, Steinert Y, Macdonald ME, Ingram L. The importance of physician listening from the patients' perspective: enhancing diagnosis, healing, and the doctor-patient relationship. Patient Educ Couns. 2011;85(3):369-374.

23. Wanzer MB, Booth-Butterfield M, Gruber K. Perceptions of health care providers' communication: relationships between patient-centered communication and satisfaction. Health Commun. 2004;16(3): 363-383.

24. Dow AW, Leong D, Anderson A, Wenzel RP, Team VT-M. Using theater to teach clinical empathy: a pilot study. J Gen Intern Med. 2007;22(8): $1114-1118$.

25. Hojat M, Louis DZ, Markham FW, Wender R, Rabinowitz C, Gonnella JS. Physicians' empathy and clinical outcomes for diabetic patients. Acad Med. 2011;86(3):359-364.

26. Kelley JM, Lembo AJ, Ablon JS, et al. Patient and practitioner influences on the placebo effect in irritable bowel syndrome. Psychosom Med. 2009;71(7):789-797.

27. Kim SS, Kaplowitz S, Johnston MV. The effects of physician empathy on patient satisfaction and compliance. Eval Health Prof. 2004;27(3): $237-251$.

28. Langewitz W, Nübling M, Weber H. A theory-based approach to analysing conversation sequences. Epidemiol Psichiatr Soc. 2003;12(2): 103-108.

29. Squier RW. A model of empathic understanding and adherence to treatment regimens in practitioner-patient relationships. Soc Sci Med. 1990; 30(3):325-339.

30. Zimmermann C, del Piccolo L, Mazzi MA. Patient cues and medical interviewing in general practice: examples of the application of sequential analysis. Epidemiol Psichiatr Soc. 2003;12(2):115-123.

31. Margalit RS, Roter D, Dunevant MA, Larson S, Reis S. Electronic medical record use and physician-patient communication: an observational study of Israeli primary care encounters. Patient Educ Couns. 2006;61(1):134-141.

32. Shaw A, Ibrahim S, Reid F, Ussher M, Rowlands G. Patients' perspectives of the doctor-patient relationship and information giving across a range of literacy levels. Patient Educ Couns. 2009;75(1):114-120.

33. Binetti P, Meloni MC, Denaro V. [New prospects in physician-patient communication: role of the animated model] [Article in Italian]. Clin Ter. 2003;154(6):421-428.

34. Collier R. Educating patients with pictures. CMAJ. 2011;183(15): E1094.

35. Kools M, van de Wiel MW, Ruiter RA, Kok G. Pictures and text in instructions for medical devices: effects on recall and actual performance. Patient Educ Couns. 2006;64(1-3):104-111.

36. Bonds DE, Foley KL, Dugan E, Hall MA, Extrom P. An exploration of patients' trust in physicians in training. J Health Care Poor Underserved. 2004;15(2):294-306.

37. Derose KP, Hays RD, McCaffrey DF, Baker DW. Does physician gender affect satisfaction of men and women visiting the emergency department? J Gen Intern Med. 2001;16(4):218-226.

38. Elderkin-Thompson V, Waitzkin H. Differences in clinical communication by gender. J Gen Intern Med. 1999;14(2):112-121.

39. Sandhu H, Adams A, Singleton L, Clark-Carter D, Kidd J. The impact of gender dyads on doctor-patient communication: a systematic review. Patient Educ Couns. 2009;76(3):348-355.

40. Waitzkin H. Information giving in medical care. J Health Soc Behav. 1985;26(2):81-101. 
41. Beisecker AE. Aging and the desire for information and input in medical decisions: patient consumerism in medical encounters. Gerontologist. 1988;28(3):330-335.

42. Thompson SC, Pitts JS, Schwankovsky L. Preferences for involvement in medical decision-making: situational and demographic influences. Patient Educ Couns. 1993;22(3):133-140.

43. Vick S, Scott A. Agency in health care. Examining patients' preferences for attributes of the doctor-patient relationship. J Health Econ. 1998; 17(5):587-605.

44. Tuckett DA, Boulton M, Olson C. A new approach to the measurement of patients' understanding of what they are told in medical consultations. J Health Soc Behav. 1985;26(1):27-38.

45. Arora NK, McHorney CA. Patient preferences for medical decision making: Who really wants to participate? Med Care. 2000;38(3): $335-341$.
46. Brinkman WB, Geraghty SR, Lanphear BP, et al. Effect of multisource feedback on resident communication skills and professionalism: a randomized controlled trial. Arch Pediatr Adolesc Med. 2007; 161(1):44-49.

47. O'Keefe M. Should parents assess the interpersonal skills of doctors who treat their children? A literature review. J Paediatr Child Health. 2001;37(6):531-538.

48. Tongue JR, Epps HR, Forese LL. Communication skills. Instr Course Lect. 2005;54:3-9.

49. Maguire P, Pitceathly C. Key communication skills and how to acquire them. BMJ. 2002;325(7366):697-700. 


\section{Supplementary materials \\ Questionnaire investigation}

\section{Scale I. Demographic Information Survey Scale}

1. Sex.

Male Female

2. Age.

$$
18-32 \quad 33-47 \quad 48-62 \geq 63
$$

3. Level of education.
Less than middle school
Middle school to high school
More than high school

4. The first diagnosis.
Renal failure
Urolithiasis
Obstruction Tumor
Other

5. First hospitalization or not.

First Not the first

\section{Scale 2. The Medical Interview Satisfaction Scale (MISS)}

1. The doctor gave me a poor explanation of my illness.

$\begin{array}{lll}\text { Very strongly agree } & \text { Strongly agree } & \text { Agree } \\ \text { Disagree } & \text { Strongly disagree } & \text { Very strongly disagree }\end{array}$

Neutral

2. The doctor told me what my illness is.
Very strongly agree
Strongly agree
Disagree
Strongly disagree
Agree
Very strongly disagree

Neutral

3. After talking to the doctor, I know how serious my illness is.

$\begin{array}{lll}\text { Very strongly agree } & \text { Strongly agree } & \text { Agree } \\ \text { Disagree } & \text { Strongly disagree } & \text { Very strongly disagree }\end{array}$

Neutral

4. The doctor told me all I wanted to know about my illness.

$\begin{array}{lll}\text { Very strongly agree } & \text { Strongly agree } & \text { Agree } \\ \text { Disagree } & \text { Strongly disagree } & \text { Very strongly disagree }\end{array}$

Neutral

5. I am not really certain how to follow the doctor's advice.
Very strongly agree
Strongly agree
Agree
Disagree
Strongly disagree
Very strongly disagree

Neutral

6. After talking to the doctor, I have an idea of how long it will take for me to get cured from the illness
Very strongly agree
Strongly agree
Disagree
Strongly disagree
Agree
Very strongly disagree

Neutral

7. The doctor seemed interested in me as a person.

Very strongly agree

Disagree

Strongly agree

Strongly disagree

8. The doctor seemed warm and friendly to me.
Very strongly agree
Strongly agree
Disagree
Strongly disagree

9. I felt this doctor did not treat me as an equal.

Very strongly agree

Disagree

Strongly agree

Strongly disagree
Agree

Neutral

Very strongly disagree

Agree

Neutral

Very strongly disagree

Agree

Neutral 
10. The doctor seemed to take my problems seriously.
Very strongly agree
Strongly agree
Agree
Neutral
Disagree
Strongly disagree
Very strongly disagree

11. I felt embarrassed while talking to the doctor.
Very strongly agree
Strongly agree
Agree
Disagree
Strongly disagree
Very strongly disagree

Neutral

12. I felt free to talk to this doctor about private matters.
Very strongly agree
Strongly agree
Disagree
Strongly disagree
Agree

Neutral

13. The doctor gave me a chance to say what was really on my mind.
Very strongly agree
Strongly agree
Agree
Disagree
Strongly disagree
Very strongly disagree

Neutral

14. I really felt understood by my doctor.
Very strongly agree
Strongly agree
Agree
Disagree
Strongly disagree
Very strongly disagree

Neutral

15. The doctor did not allow me to say everything I had wanted to say about my problems.
Very strongly agree
Strongly agree
Disagree
Strongly disagree
Agree

Neutral

16. The doctor did not really understand my reason for coming.
Very strongly agree
Strongly agree
Agree
Disagree
Strongly disagree
Very strongly disagree

Neutral

17. I would trust this doctor with my life.
Very strongly agree
Strongly agree
Agree
Disagree
Strongly disagree
Very strongly disagree

Neutral

18. I would hesitate to recommend this doctor to my friends.
Very strongly agree
Strongly agree
Agree
Disagree
Strongly disagree
Very strongly disagree

Neutral

19. The doctor seemed to know what he/she was doing.
Very strongly agree
Strongly agree
Agree
Disagree
Strongly disagree
Very strongly disagree

Neutral

20. After talking to the doctor, I feel much better about my problems.
Very strongly agree
Strongly agree
Agree
Disagree
Strongly disagree
Very strongly disagree

Neutral

21. The doctor has relieved my worries about my illness.
Very strongly agree
Strongly agree
Agree
Disagree
Strongly disagree
Very strongly disagree

Neutral

22. Talking to my doctor has not at all helped me be relieved of my worries about my illness.
Very strongly agree
Strongly agree
Agree
Disagree
Strongly disagree
Very strongly disagree

Neutral

23. The doctor has come up with a good plan for helping me.
Very strongly agree
Strongly agree
Agree
Disagree
Strongly disagree
Very strongly disagree

Neutral 
24. The doctor's visit has not at all helped me.

Very strongly agree

Disagree
Strongly agree

Strongly disagree
Agree

Very strongly disagree
Neutral

25. The doctor seemed to know what to do for my problem.
Very strongly agree
Strongly agree
Disagree
Strongly disagree

Agree

Neutral

Very strongly disagree

26. I expect that it will be easy for me to follow the doctor's advice.
Very strongly agree
Strongly agree
Agree
Disagree
Strongly disagree
Very strongly disagree

Neutral

27. I intend to follow the doctor's instructions.

Very strongly agree

Strongly agree

Agree

Neutral

Disagree

Strongly disagree

Very strongly disagree

28. It may be difficult for me to do exactly what the doctor has told me to do.
Very strongly agree
Strongly agree
Agree
Disagree
Strongly disagree
Very strongly disagree

Neutral

29. I am not sure the doctor's treatment will be worth the trouble it will take.
Very strongly agree
Strongly agree
Agree
Disagree
Strongly disagree

Neutral

\section{Subscales}

MISS1

Distress relief

Qs 1, 2, 3, 4, 6, 20, 21, 22, 23, 24, 25

MISS2

Communication comfort

Qs 5, 11, 15, 16

MISS3

Rapport

Qs 7, 8, 9, 10, 12, 13, 14, 17, 18, 19

MISS3

Compliance intent

Qs 26, 27, 28, 29

Patient Preference and Adherence

\section{Publish your work in this journal}

Patient Preference and Adherence is an international, peer-reviewed, open access journal that focuses on the growing importance of patient preference and adherence throughout the therapeutic continuum. Patient satisfaction, acceptability, quality of life, compliance, persistence and their role in developing new therapeutic modalities and compounds to optimize clinical outcomes for existing disease states are major areas of interest for the journal. This journal has been accepted for indexing on PubMed Central. The manuscript management system is completely online and includes a very quick and fair peer-review system, which is all easy to use. Visit http://www. dovepress.com/testimonials.php to read real quotes from published authors.

\footnotetext{
Submit your manuscript here: http://www.dovepress.com/patient-preference-and-adherence-journal
} 